\title{
Efeitos da utilização de inoculantes em silagens de forrageiras sobre os teores de proteína e fibra, digestibilidade dos nutrientes, $\mathrm{pH}$, fermentação e estabilidade aeróbia
}

\section{Effects of inoculantes use in forage silages on protein and fiber levels, nutrients digestibility, $\mathrm{pH}$, fermentation and aerobic stability}

\author{
Agda Luzia de Godoy Gimenes ${ }^{1 *}$; Fernanda Barros Moreira ${ }^{2}$; \\ Ivone Yurika Mizubuti²; Elzânia Sales Pereira ${ }^{3}$
}

Resumo

A silagem de forrageiras é a principal forma de armazenamento de alimento volumoso no mundo. A ensilagem possibilita o fornecimento de alimento palatável durante todo o ano, principalmente no período de seca. Durante o processo de ensilagem, a forragem verde colocada no silo sofre transformação até a estabilização completa da massa, adquirindo as características de silagem. No intuito de melhorar o processo de fermentação, têm-se utilizado alguns inoculantes. Porém, a utilização destes, sem avaliação da qualidade nutricional da silagem pode aumentar o custo do material ensilado. Além disso, importância crescente tem sido dispensada ao processo de preservação das silagens e a sua estabilidade aeróbia, sobretudo durante o período de sua utilização. Embora algumas pesquisas mostrem efeitos benéficos da sua utilização sobre a preservação e a qualidade da silagem, foram encontrados, na literatura, vários trabalhos que mostram resultados controversos. Conclui-se que a utilização de inoculantes não deve ser considerada como substituto de manejo adequado de ensilagem, como: colheita, compactação, armazenamento e vedação. Em silagens adequadamente preparadas, a utilização de inoculantes apresenta pouco ou nenhum benefício sobre a preservação e a qualidade da silagem.

Palavras-chave: Ácido láctico, deterioração aeróbia, inoculante bacteriano, inoculante enzimático, inoculante microbiano, microrganismos aeróbios

\begin{abstract}
Forage silage is the main form of voluminous food storage in the world. The ensiling makes possible the palatable food supply during the whole year, mainly in the drought period. During the ensiling process, the green forage inside of the silo suffers many transformations until the complete stabilization of the mass, acquiring the silage characteristics. With the objective of improving the fermentation process, some farmers have been using inoculants. However, the use of these inoculants, without evaluation of silage nutritional quality can increase the material cost. Besides, a big importance has been spared to the silage preservation process and your aerobics stability, mainly during the period of your use. Several works showing controversial results were found, in the literature, although some researches have shown beneficial effects of inoculants use on silage preservation and quality. It can be concluded that the inoculants use should not be considered as substitute of ensiling appropriate handling, such as: crop, compactation, storage and closure. In silages appropriately prepared, the inoculants use presents little or any benefit on silage preservation and quality.
\end{abstract}

Key words: Aerobic microorganism, aerobic deterioration, bacterial inoculant, enzymatic inoculant, lactic acid, microbial inoculant

\footnotetext{
1 Médica Veterinária. Mestre em Ciência Animal, UEL, Londrina, PR. agdag@sercomtel.com.br

2 Professores do Departamento de Zootecnia, UEL - PR.

3 Professora do Curso de Zootecnia, UNIOESTE, Marechal Cândido Rondon - PR.

* Autor para correspondência.
} 


\section{Introdução}

A silagem de forrageiras é a principal forma de armazenamento de volumoso e a mais utilizada em todo o mundo. O método é vantajoso porque possibilita o fornecimento de alimento palatável durante todo o ano, principalmente no período de seca, onde se tem escassez na produção de forrageiras. Com a utilização deste recurso é possível aumentar a lotação das pastagens no verão e manter essa lotação no inverno sem que os animais percam peso ou diminuam a produção leiteira. Por outro lado, o processo de ensilagem exige maior emprego de capital, como equipamentos e maquinários necessários ao corte, transporte, compactação e distribuição nos cochos.

Durante o processo de ensilagem, a forragem verde colocada no silo sofre transformação até a estabilização completa da massa, adquirindo as características de silagem. O principal objetivo do processo de ensilagem é alcançar valores de $\mathrm{pH}$ suficiente para inibir o crescimento de microorganismos indesejáveis e a atividade do catabolismo enzimático da planta ensilada.

No intuito de melhorar o processo de fermentação, muitos produtores tem utilizado os inoculantes baseando-se apenas nas informações contidas nos rótulos dos produtos comerciais. Porém, a utilização sem avaliação da qualidade nutricional pode aumentar o custo do material ensilado. Além disso, importância crescente tem sido dispensada ao processo de preservação das silagens relacionando sua estabilidade aeróbia, sobretudo durante a fase de sua utilização. Em muitas fazendas, as silagens passam por vários graus de deterioração aeróbia, seja por erro de manejo ou por dimensionamentos errôneos dos silos, estragando rapidamente o material ensilado. Em termos práticos, isto pode ser verificado pelo aumento de temperatura da silagem durante o fornecimento no cocho, sendo considerado um importante critério de avaliação do processo de deterioração aeróbia.

O fornecimento de silagem estragada pode resultar na redução da ingestão e performance do animal, bem como a ingestão de micotoxinas causando doenças aos animais. Assim, a melhora na estabilidade aeróbia pode conferir substancial vantagem aos produtores. Vários estudos tem sido realizados neste sentido, incluindo o uso de ácidos, porém, estes são corrosivos aos equipamentos e seu custo é oneroso. Desta forma, a melhora na estabilidade aeróbia da silagem, pelo uso de inoculantes bacterianos e enzimáticos, tem sido explorados como uma alternativa economicamente viável. Embora algumas pesquisas mostrem efeitos benéficos da sua utilização sobre a preservação e a qualidade da silagem de milho, foram encontrados na literatura vários trabalhos que mostram resultados controversos, indicando a necessidade de mais estudos sobre os parâmetros nutricionais e estabilidade aeróbia de silagens confeccionadas com diferentes inoculantes para viabilizar a sua indicação.

Esta revisão de literatura teve como objetivo discutir os efeitos da utilização de inoculantes em silagens de forrageiras sobre a qualidade nutricional e a preservação do valor nutritivo.

\section{Ensilagem de forrageiras}

As silagens de forrageiras quando preparadas adequadamente apresentam grandes vantagens na utilização em dietas de ruminantes, devido a preservação do seu valor nutricional. Há disponibilidade de armazenamento durante longos períodos e do ponto de vista técnico, é mais simples de executar, dependendo muito menos da meteorologia do que a produção de feno.

Durante o processamento de ensilagem, toda e qualquer forragem verde colocada no silo sofre transformação até a estabilização completa da massa, adquirindo características de silagem. Esta transformação compreende um processo de fermentação, dividido em: uma fase aeróbia (fase I), curta (1 dia), onde ocorre a respiração celular da planta e das bactérias aeróbias presentes, consumindo carboidratos solúveis, com produção de gás carbônico, água e calor. Esta fase termina quando 
praticamente todo o oxigênio é eliminado do silo. Em seguida inicia-se uma fase anaeróbia (fase II), de 24 a 72 horas, onde ocorre o crescimento de bactérias produtoras de ácidos, principalmente o acético, e redução do $\mathrm{pH}$ do material ensilado para valores abaixo de 5,0. À medida que diminui o pH, diminui o crescimento das bactérias produtoras de ácido acético. A fase III compreende o desenvolvimento de outro grupo de bactérias anaeróbias produtoras de ácido láctico. Na fase IV, as bactérias ácido lácticas começam a proliferar e fermentar os carboidratos solúveis, produzindo ácido láctico e promovendo a preservação eficiente do material ensilado (HOLZER et al., 1999). Esta é a fase mais longa do processo de ensilagem e continua até o $\mathrm{pH}$ ser suficientemente baixo para inibir o crescimento de todas as bactérias, fungos e leveduras. Quando este $\mathrm{pH}$ é alcançado, significa que está em fase de preservação anaeróbia. A fase $\mathrm{V}$ compreende o armazenamento da forragem ensilada (PIONEER HI-BRED INTERNATIONAL, 1990).

O principal objetivo do processo de ensilagem é alcançar quantidade suficiente de ácido láctico para inibir o crescimento de microorganismos indesejáveis e inibir a atividade do catabolismo enzimático da planta ensilada (BOLSEN et al., 1992). Normalmente, o número de bactérias ácido lácticas é baixo (SPECKMAN et al., 1981; MUCK, 1989) e incluem principalmente espécies heterofermentativas (LINDGREN et al., 1983; MULLER et al., 1991). Em geral, os microorganismos indesejáveis são as enterobactérias, fungos e leveduras, cujas atividades são prejudiciais durante o processo de ensilagem porque competem com as bactérias ácido láctico na fermentação do açúcar (LINDGREN et al., 1984; PAHLOW, 1991).

\section{Efeitos da utilização de inoculantes sobre os teores de proteína bruta e fibras da silagem.}

O uso de inoculantes no processo de ensilagem inclui a adição de bactérias homofermentativas produtoras de ácido láctico, visando aumentar o número de bactérias desejáveis ao processo de fermentação, e produtos enzimáticos que aumentam a disponibilidade de carboidratos solúveis às bactérias e melhoram a digestibilidade da matéria orgânica.

Em alguns estudos, a melhora no valor nutricional da silagem, e conseqüentemente da performance do animal, foi associada à redução do teor de fibra desta silagem (STOKES, 1992; CHEN et al., 1994). Schaefer et al. (1989) trabalhando com inoculante bacteriano composto de Pediococcus acidilactici e Lactobacillus xylosus na concentração de $1 \times 10^{5}$ ufc/g de forragem, relataram que houve redução na concentração de fibra em detergente neutro (FDN) e fibra em detergente ácido (FDA) na silagem de milho. Da mesma forma, Silva et al. (1997) trabalhando com inoculante composto de Lactobacillus plantarum e Streptococcus faecium (PIONEER ${ }^{\circledR} 1174$ ) observaram redução no teor da FDN e aumento do teor de proteína bruta (PB) na silagem de milho. Também Stokes e Chen (1994) observaram, de maneira geral, redução de 11 a 13\% na concentração de fibras (FDN, FDA, celulose e hemicelulose).

Sheperd e Kung (1996b) utilizaram inoculantes enzimáticos com atividade de celulase e hemicelulase, em silagens confeccionadas com milho em três estádios diferentes de maturidade, e não verificaram efeito sobre o teor de composto nitrogenados da silagem em nenhum estádio de maturidade. Entretanto, altas doses de inoculantes aumentaram os teores de açúcar residual da silagem no estádio leitoso e de etanol no estádio mais avançado. Com o avanço da maturidade, a adição do inoculante enzimático resultou em decréscimo linear na FDN, FDA e conteúdo de hemicelulose da silagem de milho.

Embora algumas pesquisas mostrem efeitos benéficos da utilização de inoculantes sobre a composição química da silagem, foram encontrados na literatura alguns trabalhos que mostram resultados controversos.

Resultados de diversas investigações com inoculante composto de Lactobacillus plantarum e 
Streptococcus faecium, em silagens de milho, não mostraram diferenças quanto ao teor de fibras (HUNT et al., 1993; SANDERSON, 1993; MORAIS et al., 1996). Entretanto, estes autores observaram que o teor de FDN, hemicelulose e celulose reduziram no material ensilado comparado ao material in natura.

Kung et al. (1993), Morais e Boin (1996), Daenicke et al. (1999) e Pedroso, Freitas e Souza (2000) mostraram que não houve diferença na recuperação de matéria seca (MS) e PB em silagens confeccionadas com diferentes inoculantes bacterianos.

Ao utilizarem inoculantes enzimáticos contendo atividade de celulase e hemicelulase, Sheperd e Kung (1996a), observaram que reduziu a FDN e FDA em mini-silos tratados com inoculantes. No entanto, em silos grandes, não ocorreu esta redução, relatando que os efeitos foram inconsistentes sobre a composição da fibra da silagem de milho. Por outro lado, Eichelberger; Siewerdt e Silveira Jr. (1997) estudaram a adição de inoculante bacteriano em silagem de milho com uso ou não de soja e observaram que a inoculação aumentou o teor de FDN quando comparado com silagem não tratada.

\section{Efeitos da utilização de inoculantes sobre a digestibilidade dos nutrientes.}

Alguns pesquisadores relataram que a inoculação de forragens com bactérias homofermentativas produtoras de ácido láctico podem melhorar a digestibilidade da silagem (HARRISON et al., 1989). Guim et al. (1995) usaram inoculante microbiano e observaram melhora na digestibilidade aparente da MS, PB e nutrientes digestíveis totais (NDT) em silagem de milho com alto teor de MS (37\%), não tendo efeito em silagens com baixo teor de MS (25\%). Patterson (1993 apud WOOLFORD, 1999) também relatou que os inoculantes bacteriano e enzimático aumentaram a digestibilidade das silagens de gramíneas.
Entretanto, verifica-se que os resultados encontrados na literatura são controversos. Sanderson (1993), Morais et al. (1996) e Rodrigues et al. (2002b) demonstraram que não houve efeito da utilização de inoculantes em silagens de milho sobre a sua digestibilidade. Também, Rodrigues et al. (2002a) usando três tipos de inoculantes comerciais (bacterianos, enzimáticos e bacterianos + enzimáticos) não observaram efeito sobre a digestibilidade da silagem de sorgo.

Backes et al. (2000) descreveram que a adição de inoculante bacteriano (Lactobacillus plantarum e Streptococcus faecium) não melhorou a digestão da MS e PB da silagem de milho. Da mesma forma, Guim; Andrade e Malheiros (1995), trabalhando com silagens de capim-elefante e inoculantes microbianos observaram que os inoculantes não melhoraram a digestão da MS e da FDN.

\section{Efeitos da utilização de inoculantes sobre o pH e a fermentação da silagem}

Diversos pesquisadores relataram que inoculantes bacterianos e enzimáticos promoveram a diminuição do $\mathrm{pH}$ e aumento da concentração de ácido láctico, melhorando a fermentação do material ensilado (MUCK, 1988; FABER; LINN; OTTERBY, 1989; MUCK; BOLSEN, 1991; WEINBERG; MUCK, 1996; PATTERSON, 1993 apud WOOLFORD, 1999).

Bolsen et al. (1992), usando inoculantes bacterianos e enzimáticos, relataram que o tratamento não afetou a contagem microbiana durante o período de ensilagem, mas aumentou a sua eficiência de fermentação (maior porcentagem de ácido láctico e menor pH, ácido acético, etanol e amônia) em silagem de alfafa, e verificaram que em silagem de milho o uso do inoculante não apresentou efeito na contagem de microorganismos e nas características de fermentação durante o período de ensilagem.

Algumas investigações com inoculantes bacterianos ou enzimáticos em diferentes silagens 
(milho, sorgo e outros materiais) mostraram que não houve diferenças nas variáveis: nitrogênio amoniacal, pH e características de fermentação (SCHAEFER et al., 1989; KUNG et al., 1993; MORAIS; BOIN, 1996; PEDROSO; FREITAS; SOUZA, 2000). Trabalhando com inoculante bacteriano e com diferentes níveis de soja na silagem de milho, Eichelberger, Siewerdt e Silveira Jr. (1997) observaram que a presença do inoculante na silagem causou maior elevação do $\mathrm{pH}$ quando a silagem apresentava níveis de soja maiores que $20 \%$.

Sheperd e Kung (1996a), usando inoculantes enzimáticos com atividade de celulase e hemicelulase, observaram efeitos mínimos na fermentação da silagem. Stokes e Chen (1994) observaram que após 56 dias de ensilagem, o tratamento com inoculante enzimático não afetou o $\mathrm{pH}$ da silagem, no entanto, aumentou a concentração de ácido acético e a perda de matéria seca.

\section{Efeitos da utilização de inoculantes sobre a estabilidade aeróbia da silagem}

\section{Mecanismos de deterioração da silagem}

Manter o ambiente em anaerobiose durante a fase de fermentação e armazenamento, bem como a estabilidade aeróbia durante a fase de fornecimento no cocho, são fatores importantes para a preservação do material. Durante a ensilagem, a escassez de oxigênio e o acúmulo de ácido láctico resulta em baixo $\mathrm{pH}$, inibindo o crescimento de microrganismos e preservando os nutrientes. Entretanto, quando expostos ao ar, certos microrganismos oportunistas tornam-se ativos, consumindo nutrientes, produzindo calor e danificando o material ensilado (RANJIT; KUNG, 2000). Woolford (1990) e Kung (2001) relataram que as leveduras são os primeiros microrganismos que causam deterioração aeróbica e aquecimento da silagem. Dentre as bactérias, aquelas que produzem ácido acético passam a ser responsável pelo início da deterioração aeróbia na silagem de milho (SPOELSTRA; COURTAIN; VAN BEERS, 1988).
A deterioração da silagem quando exposta ao ar é inevitável e pode resultar em perda substancial de matéria secas (WOOLFORD, 1990), que geralmente ocorre pela interação de atividades fúngicas e bacterianas (OUDE ELFERINK et al., 1999; PAHLOW; RUSER; HONIG, 1999; TAYLOR et al., 2002). É indicada pelo aumento da temperatura e do pH (KUNG; RANJIT, 2001), devido ao metabolismo de açúcares e ácidos orgânicos causado por leveduras e bactérias (SPOELSTRA; COURTAIN; VAN BEERS, 1988), ocorrendo perdas de carboidratos solúveis e produtos finais da fermentação, reduzindo a qualidade do material ensilado (PITT; LIU; MUCK, 1991). Usualmente decresce a concentração de ácido láctico e carboidratos não estruturais, pois são usados como substrato pelos microrganismos aeróbios (OHYAMA; MASAKI; HARA, 1975; KUNG, 2001).

O processo de deterioração aeróbia sofre grande influência da compactação do material durante o processamento. Assim, quando há menos oxigênio no armazenamento da silagem, aumenta-se a estabilidade aeróbia da mesma durante o fornecimento no cocho (JOHNSON et al., 2002). O adequado fechamento do silo e a remoção de quantidade suficiente de silagem durante a fase de alimentação podem ajudar a prevenir a deterioração aeróbia (KUNG, 2001).

Os cuidados com a estabilidade aeróbia da silagem são especialmente importantes no período de verão, devido a ação da temperatura ambiente sobre a estabilidade do material. Maior intensidade de deterioração ocorre em temperatura ambiente de $30^{\circ} \mathrm{C}$, que favorece a proliferação de fungos, com maior produção de $\mathrm{CO}_{2}$ e maior aumento do $\mathrm{pH}$ (ASHBELL et al., 2002).

\section{Efeitos de inoculantes bacterianos contendo bactérias produtoras de ácido láctico.}

A inoculação com bactérias homofermentativas produtoras de ácido láctico podem melhorar a qualidade da silagem promovendo rápida e eficiente 
produção de ácido láctico e redução do $\mathrm{pH}$. Entretanto, isto parece não reduzir a quantidade de leveduras, pois estas podem crescer em $\mathrm{pH}$ baixo (LINDGREN et al., 1985). Portanto, alta concentração de ácido láctico nem sempre tem efeito positivo sobre a estabilidade aeróbia e a inibição do crescimento de leveduras (WOOLFORD, 1975).

Por este motivo, vários pesquisadores têm estudado o efeito dos inoculantes bacterianos sobre a estabilidade da silagem de milho. Os resultados da utilização de bactérias produtoras de ácido láctico são controversos. Cleale, Firkins e Van De Beek (1990) encontraram efeitos positivos, enquanto que Schaefer et al. (1989), Chen et al. (1992) e Sanderson (1993) não observaram diferenças significativas; Rust; Kim e Enders (1989) e Weinberg e Muck (1996) encontraram efeitos negativos, resultando em silagens menos estáveis à deterioração aeróbia, quando da abertura do silo.

Johnson et al. (2002) estudaram os efeitos do uso de inoculantes contendo bactérias produtoras de ácido láctico em diferentes estádios de maturidade e níveis de compactação em silagem de milho, e observaram que a inoculação apresentou tendência a aumentar a estabilidade aeróbia mais que a maturidade ou o nível de compactação.

Pitt, Liu e Muck (1991) relataram que o uso de inoculante contendo bactérias estritamente homofermentativas causaram pequeno aumento na estabilidade aeróbia na silagem de milho, porém não apresentou efeito em silagem de alfafa.

\section{Efeitos de inoculantes bacterianos contendo Lactobacillus buchneri.}

Inoculantes bacterianos contendo Lactobacillus buchneri tem sido estudados e tem mostrado resultados eficazes quanto a estabilidade aeróbia, inibindo efetivamente o crescimento e a atividade das leveduras (RANJIT et al., 1998; DRIEHUIS; OUDE ELFERINK; VAN WILKSELAAR, 1999; KUNG et al., 1999). Provavelmente isto tenha ocorrido devido a capacidade do Lactobacillus buchneri em produzir ácido acético e às vezes ácido propiônico, que são mais efetivos na inibição do crescimento de leveduras e fungos do que o ácido láctico (WEINBERG et al.,1999; KUNG; RANJIT, 2001; TAYLOR et al., 2002). Oude Elferink et al. (1999) mostraram que Lactobacillus buchneri podem também produzir outros metabólicos ainda não identificados com atividades antifúngicas.

Ranjit e Kung (2000), trabalhando com Lactobacillus buchneri, observaram diminuição de ácido lático, aumento de ácido acético e menor crescimento de leveduras (Saccharomyces, Candida, Cryptococcus e Pichia spp), prevenindo a deterioração aeróbia quando a silagem foi exposta ao ar. Resultados semelhantes foram encontrados por Taylor et al. (2002) com a mesma bactéria, porém subtipo 40788, mas não encontraram efeito na ingestão e performance dos animais. Assim, recomendaram seu uso em situações onde o enchimento do silo é demorado ou quando na abertura do silo, o mesmo possui grande superfície exposta ao ar.

Taylor e Kung (2002) relataram que o prolongado tempo de ensilagem e a alta concentração de $L$. buchneri subtipo 40788 (maior que $5 \times 10^{5} \mathrm{cfu} / \mathrm{g}$ ) aumentou a produção de ácido acético e aumentou a estabilidade aeróbia da silagem, não observando efeitos quando misturaram L. plantarum.

\section{Conclusão}

A utilização de inoculantes não deve ser considerada como substituto de manejo adequado de ensilagem, como: colheita, compactação, armazenamento e vedação.

Em silagens adequadamente preparadas, a utilização de inoculantes apresenta pouco ou nenhum benefício sobre a preservação e a qualidade da silagem.

Para a utilização de inoculantes em silagens, devese considerar o seu valor sobre o custo final do 
Efeitos da utilização de inoculantes em silagens de forrageiras sobre os teores de proteína e fibra,...

material ensilado, relacionando o custo/benefício de sua utilização.

Os resultados de pesquisa sobre os efeitos de inoculantes na qualidade da fermentação, teor de fibra, digestibilidade e desempenho animal são contraditórios, sugerindo a necessidade de mais estudos.

\section{Referências}

ASHBELL, G.; WEINBERG, Z.G.; HEN, Y.; FILYA, I. The effect of temperature on the aerobic stability of wheat and corn silage. Journal of Industrial Microbiology \& Biotechnology, New York, v.28, n.5, p.261-263. 2002.

BACKES, A. A.; SANCHEZ, L. M. B.; GONÇALVES, M. B. F.; MULLER, M.; VELHO, J. P.; RODRIGUES, M. B. Avaliação da degradabilidade ruminal "in situ" da matéria seca e proteína bruta de alguns alimentos. 2000. Disponível em: <http://www.sbz.org.br/anais2000/Ruminantes/ 1077.pdf>. Acesso em: 8 ago. 2003.

BOLSEN, K. K.; LIN, C.; BRENT, B. E.; FEYERHERM, A. M.; URBAN, J. E.; AIMUTIS, W. R. Effect of silage additives on the microbial succession and fermentation process of alfafa and corn silage. Journal of Dairy Science, Savoy, v. 75, n.11, p.3066-3083, 1992.

CHEN, J. H.; KUNG JR., L.; KNUTSEN JR., K.; KRECK, E. $\mathrm{M}$. Effect of microbial inoculants on the nutritive value of corn silage for lactating dairy cows. Journal of Dairy Science, Savoy, v.75, n. supl.1, p.271, 1992.

CHEN, J.; STOKES, M. R.; WALLACE, C. R. Effect of enzyme-inoculant systems on preservation and nutritive value of haycrop and corn silages. Journal of Dairy Science, Savoy, v.77, n.2, p.501-512, 1994.

CLEALE, R. M.; FIRKINS, J. L.; VAN DE BEEK, F. Effect of inoculation of whole plant corn forage with Pediococcus acidilactici and Lactobacillus xylosus on preservation of silage and heifer growth. Journal of Dairy Science, Savoy, v.73, n.3,p.711-718. 1990.

DAENICKE, R.; JOCHMANN, K.; GADEKEN, D.; FLACHOWSKY, G. Influence of lactic acid bacteria as inoculant in corn silage on digestibility of crude nutrients and performance of dairy cows. Landbauforschung Volkenrode, Braunschweig, v.49, n.2, p.64-69, 1999.

DRIEHUIS, F.; OUDE ELFERINK, S. J. W. H.; VAN WILKSELAAR, P. G. Lactobacillus buchneri improves aerobic stability of laboratory and farm scale whole crop maize silage but does not affect feed intake and milk production of dairy cows. In: INTERNATIONAL SILAGE CONFERENCE, 12., 1999, Uppsala .Proceedings... Uppsala: Swedwn, 1999. p.264-265.

EICHELBERGER, L.; SIEWERDT, L.; SILVEIRA JUNIOR, P. Efeitos da inclusão de níveis crescentes de forragem de soja e uso de inoculante na qualidade da silagem de milho. Revista Brasileira de Zootecnia, Viçosa, v.26, n.5, p.867874, set./out. 1997.

FABER, D.A.; LINN, J.G.; OTTERBY, D. E. Effect of a bacterial inoculant on the fermentation of high moisture shelled and ear corn. Journal of Dairy Science, Savoy, v.72, n.5, p.1234-1242, 1989.

GUIM, A., ANDRADE, P.; MALHEIROS, E. B. Efeito de inoculante microbiano sobre o consumo, degradação in situ e digestibilidade aparente de silagens de milho (Zea mays L). Revista Brasileira de Zootecnia, Viçosa, v.24, n.6, p.1045-1053, nov./dez. 1995.

GUIM, A.; RUGGIERI, A. C.; ANDRADE, P.; MALHEIROS, E. B. Efeito de inoculante microbiano sobre consumo, degradação in situ e digestibilidade aparente das silagens de capim-elefante cv. Napier (Pennisetum purpureum Schum). Revista Brasileira de Zootecnia, Viçosa, v.24, n.6, p.1054-1061, nov./dez. 1995.

HARRISON, J. H.; SODERLUND, S. D.; LONEY, K. A. Effect of inoculantion rate of selected strains of lactic acid bacteria on fermentation and in vitro digestibility of grass-legume forage. Journal of Dairy Science, Savoy, v.72, p.2421, 1989.

HOLZER, M.; MAYRHUBER, E.; DANNER, H.; MADZINGAIDZO, L.; BRAUN, R. Effect of Lactobacillus $s p$ and Enterococcus sp on ensilaging and aerobic stability. In: INTERNATIONAL SILAGE CONFERENCE. 12, 1999, Uppsala. Proceedings...Uppsala: Sweden,1999. p.270-271.

HUNT, C. W.; KEZAR, W.; HINMAN, D. D.; COMBS, J. J.; LOESCHE, J. A.; MOEN, T. Effect of hybrid and ensiling with and without a microbial inoculant on the nutritional characteristics of whole-plant corn. Journal of Dairy Science, Savoy, v.71, p.38-43, 1993.

JOHNSON, L. M.; HARRISON, J. H.; DAVIDSON, D.; MAHANNA, W. C.; SHINNERS, K.; LINDERS, D. Corn silage management: effects of maturity, inoculation, and mechanical processing on pack density and aerobic stability. Journal of Dairy Science, Savoy, v.85, n.2, p.434444, 2002.

KUNG, JR., L.; CHEN, J. H.; KRECK, E. M.; KNUTSEN, K. Effect of microbial inoculant on the nutritive value of corn silage for lactation dairy cows. Journal of Dairy Science, Savoy, v.76, n.12, p.3763-3770, 1993. 
KUNG JR., L.; RANJIT, N. K.; ROBINSON, J. M.; CHALEY, R.C. Inoculation with Lactobacillus buchneri improves the aerobic stability of barley silage. In: INTERNATIONAL SILAGE CONFERENCE. 12, 1999, Uppsala. Proceedings...Uppsala: Sweden, 1999. p.272-273.

KUNG JR., L.; RANJIT,N. K. The effect of Lactobacillus buchneri and others additives on the fermentation and aerobic stability of barley silage. Journal of Dairy Science, Savoy, v.84, n.5, p.1149-1155, 2001.

KUNG JR., L. Silage fermentation and additives. In: ANNUAL SYMPOSIUM SCIENCE AND TECHNOLOGY IN THE FEED INDUSTRY. 17, 2001, Proceedings... Carlisle (MA): T.P. Lyons, 2001.

LINDGREN, S.; LINGVALL, P.; KASPERSSON, A.; KARTZOW, A.; RYDBERG, E. Effect of inoculants, grains, and formic acid on silage fermentation. Swedish Journal of Agricultual Research, Uppsala, v.13, p.91-100, 1983.

LINDGREN, S.; PETTERSSON, K.; JONSSON, A.; LINGVALL, P.; KASPERSSON, A. Silage inoculation selects strains, temperature, witting and practical application. Swedish Journal of Agricultual Research, Uppsala, v.15, p.9-18, 1984.

LINDGREN, S.; PETTERSSON, K.; KASPERSSON, A.; JONSSON, A.; LINGVALL, P. Microbial dynamics during aerobic deterioration of silages. Journal of the Science of Food and Agriculture, London, v.36, p.765-774, 1985.

MORAIS, J. P. G.; BOIN, C. Avaliação de aditivo microbiano quanto à recuperação da matéria seca e no perfil da fermentação da silagem de milho. 1996. Disponível em: $<$ http://www.sbz.org.br/eventos/Fortaleza/ Nut_rumi/sbz579.pdf>. Acesso em: 14 ago. 2003.

MORAIS, J. P. G.; BOIN, C.; CAMPOS, F. P.; FARIA, C. P.; ROCHA, M. H. M. Efeito do inoculante bacteriano em silagem de milho quanto a digestibilidade "in vivo" $e$ fermentação. 1996. Disponível em: <http://www.sbz.org.br/ eventos/Fortaleza/Nut_rumi/sbz576.pdf $>$. Acesso em: 14 ago. 2003.

MUCK, R. E. Factors influencing silage quality and their implications for management. Journal of Dairy Science, Savoy, v.71, n.11, p.2992-3002, 1988.

MUCK, R. E. Initial bacterial numbers on Lucerne prior to ensiling. Grass and Forage Science, Oxford, v.44, n.1, p.19-25, 1989.

MUCK, R. E.; BOLSEN, K. K. Silage preservation and silage additive products. IN: BOLSEN, K.K.; BAYLOR, J. E.; McCULLOUGH. Field guide of hay and silage management in North America. Des Moines: National Feed Ingredients Association,1991.p.105-126.
MULLER, T.; FEHRMANN, E.; SEYFARTH, W.; KNABE, $\mathrm{O}$. Quality of grass silage depending on epighytic lactic acid bacteria. In: PAHLOW, G.; HONING, H. Forage Conservation Towards 2000. Braunschweig Germany: Landbauforschung Völkenrode, 1991.p.297.

OHYAMA, Y.; MASAKI, S.; HARA, S. Factors influencing aerobic deterioration of silages and changes in chemical composition after opening silos. Journal of the Science of Food and Agriculture, London, v.26, n.8, p.1137-1147. 1975.

OUDE ELFERINK, S. J. W. H.; DRIEHUIS, F.; KROONEMAN, J.; GOTTSCHAL, J. C.; SPOELSTRA, S. F. Lactobacillus buchneri can improve the aerobic stability of silage via a novel fermentation pathway: the anaerobic degradation of lactic acid to acetic acid and 1,2propanediol. In: INTERNATIONAL SILAGE CONFERENCE. 12, 1999, Uppsala. Proceedings... Uppsala: Swedwn, 1999. p.266-267.

PAHLOW, G. Role of microflora in forage conservation. In: PAHLOW, G.; HONING, H. Forage Conservation Towards 2000. Braunschweig Germany: Landbauforschung Völkenrode, 1991. p.26.

PAHLOW, G.; RUSER, B.; HONIG, H. Inducing aerobic instability in laboratory scale silages. In: INTERNATIONAL SILAGE CONFERENCE. 12, 1991.Uppsala. Proceedings... Uppsala: Swedwn, 1999 p.253-254.

PEDROSO, A. F.; FREITAS, A. R.; SOUZA, G. B. Efeito de inoculante bacteriano sobre a qualidade da silagem e perda de matéria seca durante a ensilagem de sorgo. Revista Brasileira de Zootecnia, Viçosa, v.29, n.1, p.48-52, jan/ fev. 2000.

PIONEER HI-BRED INTERNATIONAL. Pioneer forage manual: a nutritional guide. Iowa: Des Moines, 1990. p.1617.

PITT, R. E.; LIU, Y.; MUCK, R. E. Simulation of the effect of additives on aerobic stability of alfalfa and corn silages. Transaction of the ASAE, St. Joseph, v.34, n.4, p.16331641, 1991.

RANJIT, N. K.; COHEN, M. A.; SMOOT, R.C.; TAVARES, J. Y.; KUNG JR, L. The effects of Lactobacillus plantarum (L.P.), L.buchneri (L.B.) and a propionic acid-base preservative on the fermentation and aerobic stability of corn silage and the aerobic stability of TMR. Journal of Dairy Science, Savoy, v.81, n.supl.1, p.196, 1998.

RANJIT, N. K.; KUNG JR, L. The effect of Lactobacillus buchneri, Lactobacillus plantarum, or a chemical preservative on the fermentation and aerobic stability of corn silage. Journal of Dairy Science, Savoy, v.83, p.526535. 2000 . 
RODRIGUES, P. H. M.; SENATORE, A. L.; STEFANO, J. T. A.; RUZANTE, J. M.; LUCCI, C. S.; LIMA, F. R. Efeitos da adição de inoculantes microbianos sobre a composição bromatológica e perfil de fermentativo da silagem de sorgo produzida em silos experimentais. Revista Brasileira de Zootecnia, Viçosa, v.31, n.6, p.2373-2379, nov./dez. 2002a.

RODRIGUES, P. H. M.; ANDRADE, S. J. T.; RUZANTE, J. M.; LIMA, F. R.; MELOTTI, L. Valor nutritivo da silagem de milho sob o efeito da inoculação de bactéria ácidolácticas. Revista Brasileira de Zootecnia, Viçosa, v.31, n.6, p.2380-2385, 2002b.

RUST, S. R.; KIM, H. S.; ENDERS. G. L. Effect of a microbial inoculant on the fermentation characteristics and nutritional value of corn silage. Journal of Production Agriculture, Madison, v.2, p.235-241, 1989.

SANDERSON, M. Aerobic stability and in vitro fiber digestibility of microbially inoculated corn and sorghum silages. Journal of Dairy Science, Savoy, v.71, p.505-514, 1993.

SCHAEFER, D. M.; BROTZ, P. G.; ARP, S. C.; COOK, D. K. Inoculation of corn silage and high-moisture corn with lactic acid bacteria and its effect on the subsequent fermentation and on feedlot performance of beef steers. Animal Feed Science and Technology, Amsterdam, v.25, n.1/2, p.23-38, 1989.

SHEPERD, A. C.; KUNG, L. An enzyme additive for corn silage: Effects on silage composition and animal performance. Journal of Dairy Science, Savoy, v.79, p.1760-1766, 1996a.

SILVA, A. W. L.; MACEDO, A. F.; MIGUELLUTI, D. J.; HOESCHL NETO, W. Efeito do uso de inoculante bacteriano e de diferentes proporções de grãos na massa sobre a composição bromatológica da silagem de milho. In: REUNIÃO ANUAL DA SOCIEDADE BRASILEIRADE ZOOTECNIA, 34., 1997, Juiz de Fora. Anais... Juiz de Fora: SBZ, 1997.p.170-172.

SPECKMAN, C. A.; PHILIPS, R. M.; LINNERTZ, D. P.; BERGER, J. C. A.; CARVER, L. A.; PARKER, R. B. A survey for indigenous Lactobacillus species on standing field corn at ensiling maturity. Journal of Dairy Science, Savoy, v., n.,p.53-99, 1981.
SPOELSTRA, S. F;; COURTAIN, M. G.; VAN BEERS, J. A. C. Acetic acid bacteria can initiate aerobic deterioration of whole crop maize silage. Journal of Agriculture Science, Cambridge, v.111, p.127-132, 1988.

STOKES, M. R. Effects of an enzyme mixture, an inoculant, and their interaction on silage fermentation and dairy production. Journal of Dairy Science, Savoy, v.75, n.3, p.764-773. 1992.

STOKES, M. R.; CHEN, J. Effect of an enzyme-inoculant mixture on the course of fermentation of corn silage. Journal of Dairy Science, Savoy, v. 77, p.3401-3409, 1994.

TAYLOR, C. C.; KUNG JR, L. The effect of Lactobacillus buchneri 40788 on the fermentation and aerobic stability of high moisture corn in laboratory silos. Journal of Dairy Science, Savoy, v.85, p.1526-1532, 2002.

TAYLOR, C. C.; RANJIT, N.J.; MILLS, J.A.; NEYLON, J.M.; KUNG JR., L. The effect of treating whole-plant barley with Lactobacillus buchneri 40788 on silage fermentation, aerobic stability, and nutritive value for dairy cows. Journal of Dairy Science, Savoy, v.85, n.7, p.17931800, 2002.

WEINBERG, Z.G.; SZAKACS, G.; ASHBELL, G.; HEN, Y. The effect of Lactobacillus buchneri and L. plantarum, applied at ensiling, on the ensiling fermentation and aerobic stability of wheat and sorghum silages. Journal of Industrial Microbiology \& Biotechnology. New York, v.23, n.3, p.218-222, set, 1999.

WEINBERG, Z.G.; MUCK, R. E. New trend and opportunities in the development and use of inoculant for silage. Fems Microbiology Reviews. v.19, n.1, p.53-68, out. 1996.

WOOLFORD, M. K. Microbiological screening of food preservatives, cold sterilants and specific antimicrobial agents as potential silages additives. Journal of the Science of Food and Agriculture, London, v.26, n.2, p.229237. 1975.

WOOLFORD, M. K. The detrimental effects of air on silage. Journal of Applied Bacteriol. London, v.68, n.2, p.101-116, 1990.

WOOLFORD, M. Ciência e tecnologia na produção de silagem. Kentucky: Alltech Biotechnology Center, 1999. 